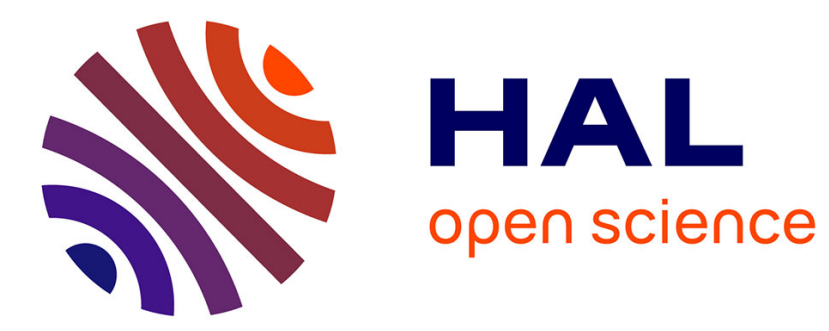

\title{
The temperature dependence of the static dielectric constant
}

P.A. Varotsos

\section{To cite this version:}

P.A. Varotsos. The temperature dependence of the static dielectric constant. Journal de Physique Lettres, 1978, 39 (7), pp.79-82. 10.1051/jphyslet:0197800390707900 . jpa-00231447

\section{HAL Id: jpa-00231447 https://hal.science/jpa-00231447}

Submitted on 1 Jan 1978

HAL is a multi-disciplinary open access archive for the deposit and dissemination of scientific research documents, whether they are published or not. The documents may come from teaching and research institutions in France or abroad, or from public or private research centers.
L'archive ouverte pluridisciplinaire HAL, est destinée au dépôt et à la diffusion de documents scientifiques de niveau recherche, publiés ou non, émanant des établissements d'enseignement et de recherche français ou étrangers, des laboratoires publics ou privés. 


\title{
LE JOURNAL DE PHYSIQUE-LETTRES
}

\author{
Classification \\ Physics Abstracts \\ $66.30 \mathrm{D}-66.30 \mathrm{H}-77.40$

\section{THE TEMPERATURE DEPENDENCE OF THE STATIC DIELECTRIC CONSTANT}

\author{
P. A. VAROTSOS
}

Westfälische Wilhelms-Universität, Institut für Theoretische Physik II, Steinfurter Strasse 107, D-44 Münster, W. Germany

(Reçu le 3 octobre 1977, révisé le 12 décembre 1977, accepté le 20 février 1978)

\begin{abstract}
Résumé. - On montre que l'accroissement de la constante diélectrique statique $\varepsilon$ des halogénures alcalins avec la température est exclusivement dû à des effets d'anharmonicité. On donne une formule simple qui permet le calcul de $\varepsilon$ à toute température si l'on connaît : (i) $\varepsilon$ à la température ambiante et (ii) les variations thermiques du module de compression et du paramètre de réseau. On discute en outre l'explication avancée par Flynn de la grande entropie de formation des défauts de Schottky.
\end{abstract}

\begin{abstract}
It is shown that in alkali halides the increase of the static dielectric constant $\varepsilon$ with temperature is exclusively due to anharmonic effects. A simple formula is given which permits the calculation of $\varepsilon$ at any temperature if we know : (i) the dielectric constant at room temperature and (ii) the thermal variation of bulk modulus and of the lattice parameter. Furthermore Flynn's explanation for the high formation entropy per Schottky defect is discussed.
\end{abstract}

Experiments show that in alkali and silver halides the static dielectric constant $\varepsilon$ increases rapidly with temperature $[1,2]$. It was initially thought that this temperature dependence could be attributed to oriented dipoles of the Debye type. However, after a careful analysis of the experimental values, by separating the contribution due to permanent dipoles, a strong increase of $\varepsilon$ with temperature $(30-40 \%$ up to the melting point $T_{\mathrm{m}}$ ) remained. This dependence is usually given in the literature in the form $[3,4]$

$$
C_{1}+C_{2} \exp \left(-\frac{E}{k T}\right)
$$

$\left(C_{1}, C_{2}\right.$ constants and $E$ thermal activation energy of the order of some hundreds of eV), or in a polynomial form $[4,5]$ of 3 rd order.

Recently, Flynn [6] pointed out that the high formation entropy $s(\approx 10 k)$ of a Schottky defect in alkali halides can be explained if the above temperature dependence of $\varepsilon$ is taken into account.

The object of the present paper is to discuss the above temperature dependence of $\varepsilon$ on a macroscopic basis. We obtain a simple relation which permits the calculation of $\varepsilon$ at any temperature if we know (i) the dielectric constant at one temperature (for instance at R.T.), (ii) the temperature variation of

To the memory of Antonios Varotsos. elastic constants, and (iii) the volume expansion coefficient. Although it is clear from the following procedure that an accurate but very complicated theoretical expression can be derived, we thought that, as a first step, it would be better to give a simple formula which can be used easily for various purposes. As an example the knowledge of the function $\varepsilon=f(T)$ is necessary in order to handle accurately the Lidiard-DebyeHückel correction [7] in the analysis of the conductivity or diffusion data of alkali and silver halides.

1. Theory. - When an ionic crystal $\mathrm{A}^{+} \mathrm{B}^{-}$does not contain permanent dipoles, such as divalent impurity-cation vacancy pairs etc., its static dielectric constant $\varepsilon$ has two sources : the electronic and the ionic polarization. The classical Lorentz-Lorentz equation can be written as :

$$
\frac{\varepsilon-1}{\varepsilon+2}=\frac{4 \pi}{3} n\left(a_{+}+a_{-}\right)+\frac{4 \pi}{3} n a
$$

where $a_{+}, a_{-}$are the electronic polarizabilities of the cation and anion respectively, $a$ is the ionic polarizability of the pair $\left(\mathrm{A}^{+}, \mathrm{B}^{-}\right)$and $n$ is the number of cations (or anions) per unit volume. If we denote by $l$ the lattice constant of the crystal it is clear that in a $\mathrm{NaCl}$-structure : $n=4 / l^{3}$ and thus Eq. (1) gives :

$$
\frac{\varepsilon-1}{\varepsilon+2}=\frac{16 \pi}{3 l^{3}}\left(a_{+}+a_{-}\right)+\frac{16 \pi}{3 l^{3}} a .
$$


If we plot the function $\frac{\varepsilon-1}{\varepsilon+2} v s \varepsilon$, a hyperbola is obtained which meets the horizontal axis at $\varepsilon=1$, and tends to 1 when $\varepsilon \rightarrow \infty$. For $\mathrm{NaCl}$ at R.T. we have [8] $\varepsilon=5.93$ and thus $\frac{\varepsilon-1}{\varepsilon+2}=0.621$. One sees that a small variation of the right-hand side of Eq. (2) leads to a large variation of the value of $\varepsilon$; for instance if the right-hand side becomes 0.666 , the value of $\varepsilon$ increases to 7 .

Let us now consider the simplified case of a harmonic solid. None of the terms $\left({ }^{1}\right)$ involved in the righthand side varies with the temperature and thus we conclude that in the harmonic approximation $\varepsilon$ seems to be roughly constant with the temperature.

We now consider the hypothetical case of an anharmonic solid with expansivity but with polarizabilities $\left(a_{+}, a_{-}\right.$and $\left.a\right)$ that do not change with temperature. From the definition of the volume expansion coefficient we get :

$$
l^{3}=l_{0}^{3} \exp \int_{0}^{T} \beta \mathrm{d} T
$$

where $l_{0}$ corresponds to $T=0$.

The value of the exponential term for $T=T_{\mathrm{m}}$ is about 1.15 in the case of $\mathrm{NaCl}$ [9]. This means that the second member of Eq. (2) decreases $15 \%$ up to $T_{\mathrm{m}}$ and thus we obtain $\varepsilon\left(T=T_{\mathrm{m}}\right)=4.52$. This is a decrease of $\varepsilon$ by $30 \%$ in comparison to R.T. value. Therefore the assumption that all three polarizabilities are temperature independent leads to a contradiction with experiments.

We now proceed to a consideration of the case where all three polarizabilities change with $T$. An appreciable change, however, of $a_{+}$and $a_{-}$seems to be precluded because of the well-known fact [10] that the same value of the electronic polarizability of an alkali or a halogen ion can be applied with success to the calculation of the refractive indexes of all alkali halides, in which the lattice constants vary by up to $50 \%$. Therefore it is reasonable to assume that the term $a_{+}+a_{-}$remains almost unchanged in comparison to $a$. We thus only have to examine the temperature variation of the ionic polarizability $a$.

The ionic polarizability, in a first approximation $[8$, 11 ] is given by $\left({ }^{2}\right)$ :

$$
a=\frac{e^{2}}{\omega_{0}^{2}} \frac{1}{\mu},
$$

where $e$ is the electronic charge, $\mu$ is the reduced mass and $\omega_{0}$ the frequency of the transverse optical mode.

( $\left.{ }^{1}\right)$ We assume that the electronic polarizabilities do not vary with the temperature; see the following remarks in the text.

$\left(^{2}\right)$ Formula (4) is an approximation because it neglects the correction of Szigeti's effective charge, etc. However, as will be discussed below, this does not alter the conclusions of the present paper.
It has been shown and has been confirmed experimentally $[12,13]$ that in alkali halides with $\mathrm{NaCl}$ structure $\omega_{0}$ can be expressed by :

$$
\omega_{0}^{2}=\text { const. } \frac{B l}{\mu}, \quad\left(\text { const. } \approx \frac{3}{2}\right)
$$

where $B$ is the bulk modulus. A combination of Eqs. (4) and (5) gives :

$$
a=\text { const. } \frac{e^{2}}{B l} \text {. }
$$

Eq. (6) contains two parameters that change with the temperature due to anharmonic effects. By comparing the influence of $l$, which increases slightly with the temperature ( $\sim 6 \%$ up to $T_{\mathrm{m}}$ ), with that of $B$ which decreases considerably with the temperature [14] ( $\sim 50 \%$ up to $T_{\mathrm{m}}$ ), one concludes that the ionic polarizability actually increases with $T$.

By inserting Eq. (6) into Eq. (2) we finally get :

$$
\frac{\varepsilon-1}{\varepsilon+2}-\frac{A}{l^{3}}=\text { const. } \frac{1}{B l^{4}},
$$

where

$$
A=\frac{16 \pi}{3}\left(a_{+}+a_{-}\right) .
$$

Eq. (7) describes the temperature variation of $\varepsilon$ by taking into account the temperature variation of $l$ and $B$.

Application of Eq. (7). - The constant included in Eq. (7) can be determined by taking into account (i) the constant $\left(\sim \frac{3}{2}\right)$ introduced in Eq. (5) and (ii) some Szigeti corrections [11]; the latter are unfortunately empirical. In the following, we avoid the determination of the constant in this way, which in any case would be somewhat arbitrary. This can be done by applying Eq. (7) to a temperature $T_{1}$ (for instance at R.T.), for which the values of $\varepsilon, l, B$ and $A$ are wellknown, and thus determining the value of the constant directly. Eq. (7) can now give the value of $\varepsilon$ at any temperature. By following the above procedure we finally get :

$$
\begin{aligned}
& 2 B_{1} l_{1}^{4}\left(1-\varepsilon_{1}\right)+2 A B_{1} l_{1}\left(\varepsilon_{1}+2\right)- \\
& \varepsilon=\frac{-\left(\varepsilon_{1}+2\right) B l\left(2 A+l^{3}\right)}{B_{1} l_{1}^{4}\left(\varepsilon_{1}-1\right)-A B_{1} l_{1}\left(\varepsilon_{1}+2\right)-}, \\
& -\left(\varepsilon_{1}+2\right) B l\left(l^{3}-A\right)
\end{aligned}
$$

where the subscript 1 denotes the quantities measured, for instance, at R.T., while $\varepsilon, B$ and $l$ denote the same quantities at any desired temperature.

Eq. (8) contains only experimental quantities $\left({ }^{3}\right)$

$\left({ }^{3}\right) A$ can easily be calculated from the refractive index i.e. :

$$
\frac{R^{2}-1}{R^{2}+2}=\frac{16 \pi}{3 l^{3}}\left(a_{+}+a_{-}\right)=\frac{A}{l^{3}} .
$$


and thus can be checked directly. As an example we apply it to $\mathrm{NaCl}$. At $300 \mathrm{~K}$ we have $[8,14] \varepsilon_{1}=5.93\left({ }^{4}\right)$, $A=56.44 \AA^{3}, l_{1}=5.64 \AA$ and

$$
B_{1}=0.237 \times 10^{12} \mathrm{erg} / \mathrm{cm}^{3} \text {. }
$$

The values of $l$ are known from the expansivity measurements of Srivastava and Merchant [9] whereas the $B$ values can be found from the relations :

$$
B=B_{t=0}+\left(\frac{\mathrm{d} B}{\mathrm{~d} T}\right)_{P=0} t,
$$

where $t$ is the temperature on the Celsius scale, and [14]

$$
\left(\frac{\mathrm{d} B}{\mathrm{~d} T}\right)_{P=0}=-0.11 \times 10^{9} \mathrm{erg} \cdot \mathrm{cm}^{-3} \cdot \mathrm{grad}^{-1} .
$$

Column 4 of table I contains the values of $\varepsilon$, according to Eq. (8); in column 5 we show the values of $\varepsilon$ obtained from the formula [3, 4]

$$
\varepsilon=5.4+2.7 \exp \left(-\frac{0.05 \mathrm{eV}}{k T}\right)
$$

which fits the experimental data within $1 \%$. A comparison of columns 4 and 5 shows that our calculated values agree with the experimental results. Equally good agreement is obtained for the other alkali halides by using values of the bulk modulus (and its temperature dependence) given in reference [15], the expansivity values of Srivastava and Merchant [9]

\section{TABLE I}

$\begin{array}{rcccc}1 & 2 & 3 & 4 & 5 \\ T \mathrm{~K} & l \AA & B 10^{12} \mathrm{erg} / \mathrm{cm}^{3} & \text { from Eq. (8) } \varepsilon & \text { experim. } \varepsilon \\ - & - & - & - & - \\ 300 & 5.64 & 0.237 & 5.93 & 5.93 \\ 400 & 5.6634 & 0.226 & 6.05 & 6.03 \\ 500 & 5.6898 & 0.215 & 6.18 & 6.24 \\ 600 & 5.7191 & 0.204 & 6.31 & 6.43 \\ 700 & 5.7514 & 0.193 & 6.46 & 6.58 \\ 800 & 5.7868 & 0.182 & 6.63 & 6.71 \\ 900 & 5.8251 & 0.171 & 6.81 & 6.82 \\ 1000 & 5.8664 & 0.160 & 7.04 & 6.92\end{array}$

$\left({ }^{4}\right)$ The values of $\varepsilon_{1}$ measured at R.T. vary from 5.87 to 5.93 ; the selection of the value 5.87 instead of 5.93 lowers all the $\varepsilon$ values included in the table by $\sim 1 \%$. the dielectric constants (at R.T.) given by Kittel [11] and the refractive indices from Schulman and Compton [16]; one obtains temperature dependences of the dielectric constant that agree with the experiments within $1.5 \%$.

2. Discussion and conclusions. - We have seen that the increase of the static dielectric constant with temperature is due to anharmonic effects. It seems that whereas the electronic term $\left(a_{+}+a_{-}\right)$remains practically constant with temperature, the ionic polarizability increases rapidly with $T$. Eq. (6) shows that this temperature increase of $a$ can be described mainly by the rapid decrease of the elastic constants with temperature. Due to the fact that the elastic constants of a crystal are closely correlated to the microscopic force constants [17-20], in reality, Eq. (6) shows that the temperature increase of $a$ is caused by the volume dependence of these force constants i.e. by the anharmonicity of the solid.

At very high frequencies, the right-hand side (due to the ionic polarization) of Eq. (7) vanishes so that the temperature variation of $\varepsilon_{\infty}$ is described by the term $A / l^{3}$; therefore, roughly speaking, $\varepsilon_{\infty}$ decreases slightly with the temperature due to anharmonic effects. This is in agreement with the trend of the experimental results.

Flynn [6] gave an equation that could calculate the formation entropy $s$ for a Schottky defect in alkali halides from the temperature dependence of $\varepsilon$. It gave $s$-values in the correct range [21] $5-10 \mathrm{k}$. The present paper shows that the increase of $\varepsilon$ with $T$ can be ascribed to the strong decrease of the elastic constants with temperature, in spite of the opposite effect of the expansivity. Flynn's result, therefore, is evidence that the high $s$-values of alkali halides are governed by these two effects. This coincides with recent conclusions derived from a quite different point of view $[22,23]$.

Acknowledgments. - I would like to express my sincere thanks to Pr. Wolfgang Ludwig for continuous encouragement and very useful suggestions. Thanks are also due to Drs C. Falter and W. Zierau for useful discussions. The help of Pr. Kessar Alexopoulos in the revision of the paper is greatly appreciated.

\section{References}

[1] Rao, K. V. and Smakula, A., J. Appl. Phys. 36 (1965) 3953.

[2] Fontanella, J., Andeen, C. and Schuele, D., Phys. Rev. b 6 (1972) 582.

[3] Alnatt, A. R., Pantelis, P. and Sime, S. J., J. Phis. C : Solid State 4 (1971) 1778.

[4] Sмiтh, G. C., Materials Science Center Report № 51 (Cornẹll 1962) (Unpublished).

[5] Jacobs, P. W. M. and Pantel is, P., Phys. Rev. B 4 (1971) 3757.

[6] FlynN, C. P., in Point defects and diffusion (Clarendon Press. Oxford) 1972.
[7] Barr, L. W. and Lidiard, A. B., in Physical Chemistry An Advanced Treatise, ed. W. Jost (Academic, N.Y.) 1970. Vol. X. PISI.

[8] Kamiyoshi, K. and Nigara, Y., Phys. Status Solidi (a) 6 (1971) 223.

[9] Srivastava, K. K. and Merchant, H. D., J. Phys. Chem. Solids 34 (1973) 2069.

[10] Reference [6] p. 598, Reference [11] p. 165.

[11] KitTel, C., in Introduction to Solid State Physics (2nd edition, Wiley, N.Y.) 1956 , p. 167-168. 
[12] Ferraro, J. R., Mitra, S. S. and Quattrochi, A., J. Appl. Phys. 42, 10 (1971) 3677.

[13] Postmus, C., Ferraro, J. R. and Mitra, S. S., Phys. Rev. 174 (1968) 983.

[14] Spetzler, H., Sammis, C. G. and O'Connell, R. J., J. Phys. Chem. Solids 33 (1972) 1727.

[15] Haussühl, S. Z., Z. Phys. (1960) 159, 223.

[16] Schulman, J. H. and Compton, W. D., Color centers in Solids (Pergamon Press, Oxford) 1963.

[17] LEIBFRIED, G., Gittertheorie der mechanischen und thermischen Eigenschaften der Kristalle, Handbuch der Physik, Vol. VII/I (Springer-Verlag Berlin) 1955.
[18] LeIBFried, G. and Ludwig, W., Theory of Anharmonic Effects of Crystals Solid State Phys., Adv. in Res. and Applications (ed. by F. Seitz and D. Turnbull) 1961, p. 276-444.

[19] LudwIG, W., Recent developments in Lattice theory (Springer Tracts in Modern Physics, Springer) 1967.

[20] LudwIG, W., Festkoerper Physik (Frankfurt 1970) Vol. I, p. $178-181$.

[21] Beniere, F.. J. Physique Lett. 35 (1974) 9.

[22] Varotsos, P. and Alexopoulos, K., J. Phys. Chem. Solids 38 (1977) 997 ; Phys. Rev. B 15 (1977) 4111.

[23] Varotsos, P. and Alexopoulos, K., J. Physique Lett. 38 (1977) 329. 